\title{
The Use of Eggs and Embryos in Stem Cell Research
}

\author{
Robert Klitzman, M.D. ${ }^{1}$
}

Stem cell research has enormous potential to advance knowledge about many diseases but poses critical ethical issues. Many countries and U.S. states have developed policies concerning this area that over time will surely evolve, yet certain underlying ethical principles and tensions will no doubt continue to remain key. Overall, the basic ethical principles of autonomy, beneficence, nonmalfeasance, and justice are crucial but have been viewed, interpreted, and applied differently by policy makers and others. Controversies remain concerning what degree of respect eggs and embryos should receive; whether egg donors should be compensated, and if so, how much; what exactly to include in informed consent; and how to ensure appropriate oversight by institutional review boards and embryonic stem cell research oversight committees. This article addresses these areas and ways of approaching them, to adhere to important ethical principles, while helping to advance research that has the potential to help innumerable patients.

KEYWORDS: Ethics, policy, coercion, exploitation, informed consent

The use of eggs and embryos in stem cell research raises many critical ethical issues. Human embryonic stem cell (HESC) research more broadly has been one of the most controversial topics in contemporary medical science, capturing the attention of scientists, physicians, politicians, theologians, and the lay public-all of whom struggle for consensus on how best to proceed in the development and proper use of this research.

Over recent years, many countries and U.S. states have developed policies concerning these areas and over time will surely reevaluate and potentially alter these, yet certain underlying ethical principles and tensions will no doubt continue to remain vital for clinicians and researchers to be aware of.

${ }^{1}$ Division of Psychiatry, Law and Ethics; Ethics and Policy Core, Columbia University, New York State Psychiatric Institute, New York, New York.

Address for correspondence and reprint requests: Robert Klitzman, M.D., Division of Psychiatry, Law and Ethics; Ethics and Policy Core, HIV Center, College of Physicians and Surgeons; and Joseph Mailman School of Public Health, Columbia University, New York State Psychiatric Institute-Unit 15, 1051 Riverside Drive, New York, NY
Overall, as summarized on Table 1, several ethical issues are critical in this area.

As described more fully later in this article, the basic ethical principles, as presented in the Belmont Report, ${ }^{1}$ of autonomy, beneficence, nonmalfeasance, and justice are key. But over time, policy makers have viewed, interpreted, and applied these principles in varying ways. Clearly, autonomy is crucial, and many argue that woman thus have a right to do with their bodies as they wish, providing they are not harming others. Hence, many aver, women should have the right to decide what to do with their oocytes and to donate eggs for research. Women who consider donating their oocytes should decide freely and not be coerced.

10032 (e-mail: Rlk2@columbia.edu).

Ethical Controversies in Reproductive Medicine; Guest Editor, Mark V. Sauer, M.D.

Semin Reprod Med 2010;28:336-344. Copyright (C) 2010 by Thieme Medical Publishers, Inc., 333 Seventh Avenue, New York, NY 10001, USA. Tel: +1(212) 584-4662.

DOI: http://dx.doi.org/10.1055/s-0030-1255182.

ISSN 1526-8004. 
Table 1 Ethical Issues Posed by the Use of Eggs and Embryos in Stem Cell Research

Underlying principles

- Autonomy: respect of donor

- Beneficence: enhancing individual and social benefit

- Nonmalfeasance: minimizing risks to donors

- Justice: ensuring that the risks and benefits of research are equitably distributed

Questions and controversies

- What degree of respect should eggs and embryos receive, and what are the implications for research?

- Do embryos constitute "human life"?

Applications of principles: ongoing questions

- Compensation and informed consent:

- Should egg donors be compensated, and if so, how much?

- What exactly should be included in informed consent?

- Up-to-date information about potential risks

- Using understandable lay language

How to ensure appropriate oversight:

- By institutional review boards

- By embryonic stem cell research oversight committees

- By governmental agencies

Beneficence and nonmalfeasance (i.e., the notion, "first do no harm") are vital, to ensure that providers try to help and avoid harming patients. Justice mandates that research be conducted in a way that is fair and just from a social perspective. As far as possible, the burdens of research should not fall disproportionately on any one group. In addition, any benefits that stem cell research provides for eventual treatments of disease should be fairly distributed.

But some religious and moral groups question whether embryos themselves have rights, in part reflecting religious beliefs. In addition, individuals may weigh these four general principles differently. Hence, the use of eggs and embryos in stem cell research occurs in a diverse pluralistic society, in which opposing views cannot always simply be dismissed but often must be respected and approached with sensitivity.

Given the controversies surrounding these issues, governments in the United States and other countries have issued laws and guidelines, which have tended to evolve over time, in part due to scientific advances, improved public understandings of the issues involved, and changes in public opinion. In the United States, the history of the development of these regulations is critical to bear in mind, as it establishes the political, ethical, and clinical contexts in which providers and patients now operate, and this history will shape the evolution of issues in this area.

\section{HISTORICAL PERSPECTIVES}

Over the past few decades, responses to these basic ethical tensions have shifted.

First developed in the 1980s, stem cells were quickly viewed by many scientists as holding enormous promise in helping to enhance understandings and treatments of numerous neurological, cardiac, endocrine, and other disorders, from Alzheimer's to diabetes. Following the first live birth using in vitro fertilization (IVF) - that of Louise Brown in England-the governments in the United States and elsewhere began to issue regulations concerning experimentation on human embryos. Early consensus banned the use of eggs and embryos for reproductive cloning, given widespread moral concerns about eugenics and potential abuses.

Yet controversies have emerged ever since as to what else exactly should be regulated, and how. Importantly, questions have remained as to whether individuals should be allowed to donate eggs and/or embryos for research, and if so, when, how, who, and with what limitations, if any. These areas remain contentious, and as of this writing, consensus is still forming about some realms, but remains in flux about others.

In the United States, Congress and President Clinton permitted the National Institutes of Health (NIH) in 1993 to fund research on human embryos left over from IVF. Yet in 1995, Congress attached the Dickey Amendment to the NIH appropriation bill, prohibiting the use of federal funds to create or destroy embryos, whether those embryos were from IVF or created for purposes of research. ${ }^{2}$ On the one hand, many couples who have undergone IVF may have extra embryos remaining, and some individuals have argued that these, and only these, should be used for stem cell research. On the other hand, many scientists have argued that obtaining eggs of the highest quality is important to optimize the success of research (e.g., the development of new therapies), and that eggs should thus be as fresh as possible, rather than frozen. Moreover, embryos that were rejected for use in IVF may not be as viable or as high quality in various ways. Somatic cell nuclear transfer (SCNT) is best performed using fresh eggs that are enucleated, so that a desired somatic cell nucleus can be fused to create a unique cell line carrying the specific traits desired for study.

For over 20 years, many women have donated eggs for reproductive purposes in order to assist other adults who wish to have children, but are unable to do so because they are infertile or for other reasons. Hence, many researchers sought to obtain fresh oocytes for purposes of research.

In 1999, Harriet Rabb, a lawyer in Clinton's Department of Health and Human Services, argued that NIH could fund research on HESCs, once these were already created, because these were not human embryos per se. ${ }^{3}$ 
Yet, in August 2001, President George W. Bush banned use of federal monies for any embryonic stem cell research, except on lines that then already existed. He stated that 78 lines would qualify, but the number of such lines proved to be far less (19 to 21). ${ }^{4}$ Bush's ban reflected moral objections to stem cell research. Many religious conservatives, pro-life, anti-abortion activists, and others argue that embryos are themselves human life and hence should not be created for research or destroyed. Bush's decisions met with widespread public disapproval. Many other religions and individuals define the start of life differently and argue that eggs and embryos deserve great respect, but do not, in and of themselves, constitute "life." Hence, donation and use of eggs and embryos in research may be justified, providing such respect is maintained and the research is aimed to provide important social benefits. ${ }^{5}$ Congress supported extending stem cell research and passed bills aiming to permit research on embryos left over in IVF clinics, yet President Bush then vetoed this legislation.

Researchers pursued avenues outside federal grants, including private philanthropy. In November 2004, California voters passed Proposition 71, which allowed the state to issue a $\$ 3$ billion bond to support HESC research. This proposition led to the creation of the California Institute for Regenerative Medicine (CIRM). Yet institutions had to ensure that no federal funds were used in any way in this research (e.g., paying for the maintenance of labs or buildings in which the research occurred.)

In 2006, in response to ongoing research funded by states and private philanthropy, the National Academy of Sciences (NAS) released guidelines concerning ethical issues raised by stem cell research. ${ }^{6}$ These guidelines did not address sources of funding but rather concerns regarding the protection of the rights of participants in the research. The guidelines focused on informed consent and local institutional oversight of the research. The NAS subsequently amended these guidelines in $2007^{7}$ and $2008 .^{8}$ These guidelines do not constitute federal law or regulations- they are nonbinding. Yet, many have seen them as establishing a standard in certain ways, though over time, controversies have remained.

The NAS banned certain types of studies outright - specifically, any research on reproductive cloning and research on culture of embryos, regardless of their sources, for more than 14 days or until the formation of the primitive streak. The guidelines also prohibited certain kinds of research that create so-called "chimeras" that mix human and nonhuman primate cells (e.g., research in which embryonic cells from humans are entered in nonhuman primate blastocysts).

The NAS stipulated that for research that involves human participants (e.g., as egg donors), institutional review boards (IRBs), or research ethics committees as they are often called in other countries, need to review and approve protocols. Informed consent was needed and had to be given voluntarily, without coercion.

The guidelines also mandated the establishment of institutional embryonic stem cell research oversight committees (ESCROs) that would oversee all issues concerning derivation and use of HESC. These committees would review the scientific merit of research protocols and maintain registries (that will be made public) of all lines used at an institution. Parent institutions are responsible for monitoring their ESCROs.

The guidelines also covered the procurement of eggs and embryos for research, stipulating that donors provide informed consent at the time the eggs (or embryos) are provided to researchers. That is, even though a couple may indicate while undergoing IVF that they are willing to have excess embryos used for stem cell research, formal consent should be obtained when this material is in fact donated.

The guidelines enumerated several elements to include in the informed consent, such as:

- Donors' right to withdraw their consent until their donated material is in fact used in research

- Risks to the donor

- The fact that embryos will be destroyed in the process of developing HESCs

- The fact that the research might generate commercial gains, but that the donors will not receive any financial benefit as a result

- The fact that cells might be kept for long periods of time

- Statements concerning privacy and confidentiality (e.g., whether the donors' identity will be available to researchers)

- Statements as to whether the donor can dictate what kind of research is conducted on the material (e.g., for SCNT or not)

As will be discussed more fully later, NAS banned compensation to oocyte donors beyond reimbursement of basic expenses, such as travel. ${ }^{6-8}$ The NAS also required documentation of the provenance of cells lines used (i.e., documentation of the process through which this material was obtained).

Still, many researchers and others felt that NAS guidelines were too restrictive, and in part as a result, the International Society for Stem Cell Research (ISSCR) issued guidelines as well in December 2006. ${ }^{9}$ These guidelines, although adhering to the same broad ethical principles as those of the NAS, were more permissive in a few critical regards. Most importantly, they opened the door to possible compensation, saying, "Reimbursement for direct expenses incurred by donors as a consequence of the consent process may be determined during the ESCRO process". ${ }^{10}$ 
In 2007, Eliot Spitzer and David Patterson took office as Governor and Lieutenant Governor of New York, after running on a platform that included support for stem cell research. Their administration then allocated $\$ 600$ million for stem cell research over 10 years.

In March 2009, the Obama Administration issued draft guidelines, which were open to public comment. The NIH received 49,000 comments and released final revised guidelines in May 2009. Of note, these guidelines permitted far more research on stem cells than had been permitted under President Bush. Specifically, they allowed research on cell lines that had been developed using nonfederal funds (e.g., from private philanthropy) since Bush's August 2001 ban. However, these lines also must have been created from embryos left over from IVF treatment, rather than been created for the purposes of research. Obama's new regulations also specified that the Working Group of the Advisory Committee to the Director would review on a case-by-case basis the use of cell lines for which full documentation of all of the above requirements was not available, or where it may not be possible or feasible to recontact couples. This committee would then advise the NIH. The NIH would also create a registry of all such lines on which federally funded research was allowable.

However, many scientists and patient advocates felt that Obama did not go far enough. Specifically, he has not permitted the use of federal funds to develop new lines from sources other than leftover embryos from IVF clinics. The Dickey Amendment appears to be the primary obstacle. This law was passed by Congress and hence many observers feel that only Congress can overturn it. Though many scientists and patient groups have hoped that Congress would consider overriding this amendment, as of this writing that has not yet occurred, in part no doubt due to concerns about the ethical and political divisiveness of the issue.

Table 2 summarizes the status as of September 1, 2009 of fundability for various types of stem cell research (e.g., from embryos "left over" in IVF clinics or created by oocyte donation for research purposes, and for derivation versus future uses of cell lines).

Another recent development relevant to these issues has been the creation of induced pluripotent stem cells. Scientists have been able to "reprogram" skin cells to revert to being pluripotent stem cells. ${ }^{11}$ On the one hand, some opponents of SCNT have argued that this development makes these prior ethical controversies moot, as HESC is no longer needed, and induced pluripotent stem cells can simply be used instead. However, many leading scientists have argued that both HESC and induced pluripotent stem cells remain vital, because neither has yet been developed to the point of producing treatments, and much research is needed on both in order to evaluate and compare them.

Of note, in the United Kingdom, the Human Fertilization and Embryology Authority (HFEA) has also permitted so-called "egg sharing," in which women undergoing their own IVF treatment can donate extra eggs (for purposes of reproduction or research, albeit only in a licensed research project) and receive their treatment for free or reduced rates. Yet the HFEA has prohibited payment to any other egg donors. ${ }^{12}$ Suggestions have also been made to allow women in poorer countries to provide eggs to women in wealthier countries through egg sharing in return for free or less expensive IVF treatment. ${ }^{13}$ Such eggs from poorer countries could presumably also be used for research. Yet such international use of embryos may pose particular ethical concerns, given cultural and economic differences between countries. Moreover, importantly, the use

Table 2 Use of Eggs and Embryos in Stem Cell Research and Research Fundability (as of September 2009)

\begin{tabular}{|c|c|c|c|}
\hline \multirow[b]{2}{*}{ Procedure } & \multicolumn{3}{|c|}{ Funded by* } \\
\hline & $\begin{array}{l}\text { U.S. Federal } \\
\text { Government }\end{array}$ & $\begin{array}{l}\text { New York State } \\
\text { and Private Sources }\end{array}$ & $\begin{array}{l}\text { Several } \\
\text { Other States }\end{array}$ \\
\hline Embryo obtained from in vitro fertilization & No & Yes & Yes $^{\dagger}$ \\
\hline Stem cell line developed & No & Yes & Yes $^{\dagger}$ \\
\hline Stem cell line researched & Yes & Yes & Yes \\
\hline \multicolumn{4}{|l|}{ Embryo created using oocyte donations } \\
\hline With payment for donations & No & Yes & No \\
\hline Stem cell line developed & No & Yes & No \\
\hline Stem cell line researched & No & Yes & No \\
\hline \multicolumn{4}{|l|}{ Embryo created using oocyte donations } \\
\hline Without payment for donations & No & Yes & Yes \\
\hline Stem cell line developed & No & Yes & Yes \\
\hline Stem cell line researched & No & Yes & Yes \\
\hline
\end{tabular}

*Note: Fundability also requires that eggs and embryos were procured following appropriate informed consent guidelines, based on documentation or assessment by Advisory Committee to the Director of National Institutes of Health.

†े If no compensation was given for oocyte. 
of embryos acquired through egg sharing usually does not advance research goals for SCNT, which aims to produce disease-specific and patient-specific stem cells. Embryos remaining from preimplantation genetic diagnosis could produce disease-specific stem cell lines but have also been frozen, which likely impairs their usefulness; and unused embryos may have been initially unselected because they appeared in fact less viable in morphology or development. Hence, they may be less efficacious for research purposes, too.

\section{CURRENT AND FUTURE ISSUES}

Clearly, many questions and controversies remain and will surely continue to evolve over upcoming years, decided by the stakeholders involved.

\section{Compensation of Egg Donors}

As mentioned earlier, whether egg donors may be compensated beyond reimbursement for basic expenses such as travel to include their time and burden remains fiercely debated in both the United States and Europe. Although the NAS opposes such payments, researchers found that this ban impeded important research. In line with NAS policy, CIRM also banned such compensation and prohibited use of eggs left over from donation for reproductive purposes, where the donors received compensation more than that for time and travel. Massachusetts similarly adopted NAS guidelines. Several arguments for and against payment for egg donation for HESC have been presented. ${ }^{14-19}$

Opponents to additional payment have included religious conservatives, who argued that payment did not adequately respect human dignity; similarly some feminists have felt that payment represented commoditization of the body, that eggs should not be bought or sold in any way, and that donation in which participants are compensated constitutes such sale. They asserted that compensation might result in undue inducement and exploitation ${ }^{20}$ - that women might end up providing eggs for research because of financial need and might discount the physical and psychological risks of donation. These opponents have stated that eggs should not be bought and sold like other commodities, because to do so would represent a lack of respect and dignity. These critics have suggested, too, that permitting payment might disincentivize altruistic donation, ${ }^{21}$ that poorer women might disproportionately donate more than wealthier women, that donors of blood and organs are not similarly compensated; and that as an alternative, embryos could be provided by women already undergoing IVF. Of note, many critics of compensation in fact oppose HESC as a whole.

Yet, in contrast, others have argued that payment does not necessarily undermine critical underlying eth- ical principles. Egg donation is relatively safe. However, women do confront potential physical and psychological risks in the process. They undergo ovarian hyperstimulation, retrieval of eggs, and weeks of treatments. Gonadotropins may possibly heighten the risk of ovarian cancer, ${ }^{22}$ though well-designed studies have failed to demonstrate a relationship. ${ }^{23,24}$

Hence, given the time commitment, inconvenience, and potential risks, many scientists and ethicists argue that compensation may be reasonable. In addition, importantly, donors for reproductive purposes have been compensated for undergoing the identical procedure, with identical risks, for over 20 years. Thus, for women to receive less compensation when donating for research, as opposed to clinical purposes, in fact appears unjust. Moreover, current NAS restrictions, based on fears of undue inducement, may be overly paternalistic. "Undue inducement" and "coercion," though prohibited in federal regulations, ${ }^{25}$ remain ill defined and conceptually unclear. ${ }^{5,26}$ Additionally, scholars have forcefully argued that IRBs define these concepts too broadly and are unduly concerned about these phenomena. Coercion may in fact rarely occur ${ }^{27}$; no data have been published as to whether it occurs and, if so, how frequently. Admittedly, extremely high payments, beyond a certain limit, could pose ethical concerns, but that potential fact should not prevent lesser, more reasonable compensation. Furthermore, arguably, compensation is offered not for eggs, but for women's time and risk. ${ }^{28}$

Though opponents to compensation argue that blood and living organ donors are not paid and that egg donors should thus not be, either, blood donation involves minimal risk, and living organ donors usually offer these organs only to close family members. Hence, these examples differ from the case of egg donation. Similarly, though opponents to compensation argue that eggs and embryos remaining from IVF could be used in research instead, as mentioned above, these so-called "leftover" embryos were often not selected because they appeared less viable. They have also often been frozen, which likely impairs their viability. Key avenues of research require disease-specific and patient-specific stem cells, and hence, optimal science necessitates fresh eggs.

Importantly, arguments against compensation were presented before researchers, funded by states and private philanthropy, began to try to recruit donors. The initiation of attempts by researchers to recruit donors without providing payment has revealed enormous challenges. Specifically, hundreds of women have donated eggs for clinical (i.e., reproductive purposes) through which they receive compensation beyond that for travel (i.e., at present, approximately $\$ 8000$ ). However, in the absence of such payment, donations for research purposes have generally not been successful. At Harvard, for example, which has one of the largest and most successful research groups, years of major recruitment efforts 
including costly advertising campaigns have led to interest from hundreds of women. But all but one potential donor subsequently declined to participate when told that compensation would be only for direct expenses. One privately funded researcher reported in 2006 paying donors (an average of $\$ 3573$ per egg) and being able to recruit donors. ${ }^{29}$

Hence, The American College of Obstetrics and Gynecology (2007) ${ }^{30}$ and American Society for Reproductive Medicine (ASRM; 2007) ${ }^{28}$ developed guidelines supporting reasonable compensation. ISSCR guidelines have opened the door to possible payment as well, stating, "Reimbursement for direct expenses incurred by donors as a consequence of the consent process may be determined during the SCRO process."

Subsequent research ${ }^{31}$ has found that of women donating eggs for clinical purposes, $93 \%$ believed that women should be able to donate their eggs for research as well, and $82 \%$ would be willing to do so. Most were not aware that compensation for such donation was illegal; 74\% thought that they should be compensated the same whether they were donating for reproductive or research purposes, but most would not still consider donation if payment was limited to travel expenses alone. When asked what minimum amount they felt they should be compensated, the modal response was in fact \$8000, which accords with ASRM guidelines.

Thus, the essential failure of recruitment efforts in the absence of payment has impeded scientific progress and the potential development of treatments that could benefit countless patients. Hence, from the point of view of justice, the needs of these patients should be included in the ethical analysis.

Given these inequities in rates of compensation, in June 2009, New York's Empire State Stem Cell Commission decided to permit compensation for egg providers, commensurate with standards developed and described by the ASRM for donation for clinical (i.e., reproductive purposes). Specifically, the compensation should not surpass an appropriate amount (as of this writing, "at this time sums of $\$ 5000$ or more require justification and sums above $\$ 10,000$ are not appropriate"). ${ }^{32}$ This state's provisions included strict guidelines as to the oversight and the amount of compensation. Specifically, as with ASRM guidelines, such compensation had to be carefully reviewed by both an ESCRO and IRB, and researchers need to ensure that thorough and complete informed consent occurred and that coercion and exploitation did not occur. Subsequently, CIRM has decided to reevaluate its policies.

As suggested previously, the underlying ethical bases of these decisions were that autonomy dictates that women have the right to evaluate the potential risks and benefits for themselves. This policy enhances beneficence, as the purpose of donation is to help patients through research that might lead to effective treatments for conditions for which inadequate treatment now exists. Justice mandates that women who are interested in donating for research should be treated equally, and not less than, women wishing to donate for clinical purposes. Because patients needing treatment may benefit from research, policy makers should consider ways to facilitate that process, providing, of course, that other ethical principles are upheld and not violated. Thus, ethically, on balance, the benefits of providing compensation appear to outweigh the potential harms (e.g., potential coercion).

However, because justice is important, researchers should assess the characteristics of women who indeed do decide to donate, to ensure that these women are not disproportionately drawn from any one group (i.e., poorer, disadvantaged women).

\section{How Much to Compensate?}

Questions then emerge as to not only whether donors should get compensated, but how much. In general, how much study participants do or should get paid remains unclear. A few studies have suggested that amounts vary widely across institutions, IRBs, and research studies. ${ }^{33}$ Indeed, most published research studies fail to mention whether participants in fact got paid and if so, how much, though most study recruitment Web sites state that participants will be paid. ${ }^{34}$ Several models have been suggested to gauge appropriate amounts of compensation: a "market model" (reflecting supply and demand, and potentially offering high amounts for undertaking more risk), a "wage model" (providing a standardized wage ), and a "reimbursement model" (which covers expenses, including pay for missed work). ${ }^{33}$

A market model would suggest that egg donors receive the same for research as they do for clinical purposes-approximately $\$ 2000$ to $8000 .{ }^{35}$ Indeed, ASRM's guidelines for compensation for egg donation established ceilings that have increased slowly over time, reflecting increases in cost of living. Similarly, a wage model would suggest that egg donors receive the same per hour as do sperm donors. Thus, if sperm donors receive approximately $\$ 60$ to $\$ 75$ for approximately 1 hour, then egg donors, who spend about 56 hours in procedures and meetings, should be compensated the same per hour, ${ }^{36}$ or approximately $\$ 4200$. This amount is not wholly inconsistent with ASRM and ESSCB policy that requires justification for amounts over $\$ 5000$.

Careful oversight of egg donation and of compensation is crucial. Researchers need to work closely with ESCROs and IRBs to ensure that informed consent is appropriate and thorough. This area continues to evolve rapidly, with shifts in policies about funding for stem cell research by both federal and state government. Of note, if women are compensated, it may be most 
appropriate to call them egg "providers" rather than "donors."

\section{Informed Consent}

NAS guidelines indicate that informed consent is essential to ensure autonomy, yet decisions remain to be made of what exactly informed consent should include. Clearly, egg providers need to be informed of the risks and benefits of donation in a way that they understand. In all protocols, IRBs should ensure that any risks be minimized and benefits maximized and that women be fully informed of these.

Importantly, informed consent consists of not merely signing a form, but a process of interacting with donors to ensure that they understand and that any questions they have be answered. In all of these interactions, language is important, ensuring that the reading level used is not more than that of the donors. Hence, terms like blastocyst and primitive streak need to be explained.

Informed consent documents should reflect upto-date understandings of all risks involved. As more donors are followed for longer periods of time, scientific understandings of risks are advancing, with better data on the scope and prevalence of possible adverse side effects (e.g., ovarian hyperstimulation syndrome, cancer, or other complications). Moreover, issues concerning donations of eggs and embryo can vary somewhat, as a woman may be said to "own" an egg, and hence only her consent is needed, although an embryo involves both a man and a woman, and hence consent from both may be required.

\section{Consenting Twice?}

NAS guidelines stipulate that women should be consented concerning both the donation of eggs and the ways in which researchers will use these eggs. Yet, questions remain as to how specific the purposes should be at the time of the consent-for instance, perhaps specifying stem cell research on a specific organ system or disease, rather than being completely open-ended. Researchers may need to specify the funders of their research, any conflicts of interest that they may have in the recruitment process or conduct of the study, and plans for dissemination of treatments if these are developed (e.g., that researchers will try to arrange for treatments to be made as available as possible).

\section{Using Eggs and Oocytes across Political Boundaries}

Given increasing amounts of multisite collaborations between scientists, uniformity of policies can help promote research. Hence, policy makers and researchers face numerous challenges that they will no doubt address in varying ways. Due to variations in national and state policies in both the United States and other countries, issues regarding importing and exporting eggs and embryos across political boundaries will surely continue to evolve. Currently, a "patchwork quilt" of regulations has developed. Questions then arise of how to proceed if researchers wish to import eggs or cells lines developed from eggs to other jurisdictions where the regulations differ-for example, using eggs for which donors were paid in states or countries that ban such payment. Providers involved in egg and embryo donation are of course required to abide by the laws and regulations in their jurisdiction.

However, if indeed donation without compensation continues to be unsuccessful, states and countries other than New York may well consider reevaluating their current policies. If egg donation now proves successful in New York but not elsewhere, researchers might additionally decide to move to New York to pursue their research. Following New York State's decision, other states have expressed interest in reassessing their own policies. Alternatively, the current patchwork quilt of policies could continue in some form, though it may impede collaborations across political boundaries.

\section{Other Questions for the Future}

Additional questions remain concerning ESCROs. No research has been published on how these entities operate (e.g., whether they vary between institutions or states, and if so, how). Indeed, research has demonstrated that IRBs deviate widely in their decision making. ${ }^{37-41}$ Because NAS guidelines are not enforced and are nonbinding, states and intuitions may interpret and apply these in different ways. Research on how ESCROs and IRBs view and approach these areas is urgently needed.

Given concerns about justice, it is important that principal investigators, IRBs, and ESCROs carefully assess recruitment procedures and advertisements. Recruitment information has been found to usually be unbalanced, presenting benefits and payments, but not risks. ${ }^{42}$ Research is also needed on which women decide to donate eggs (e.g., whether poorer women disproportionately donate) and how donation affects donors medically and psychologically over time.

\section{CONCLUSIONS}

The use of eggs and embryos in stem cell research has posed numerous ethical problems that continue to evolve. It is vital that clinicians and researchers involved in this area be highly sensitive to the political, social, and ethical contexts in which they work and be aware of 
relevant state and federal regulations. At the same time, these will surely continue to develop, as science and public opinion alter over time.

Stem cell research has enormous potential to advance knowledge about the pathophysiology and treatment of many diseases, yet must be conducted with appropriate attention to the ethical issues it poses and differences in opinion that may exist in a diverse pluralistic society. In such a society, diverse views may be voiced. Policy makers and scientists cannot always adhere to all of these divergent views, but it is important to respect varying perspectives, even if these cannot always be followed. At the same time, it is important for researchers and clinicians to be aware of not only these critical ethical issues but also the need for ongoing education of patients, policy makers, and the broader public about these issues. Such education can help ensure that regulations are as appropriate as possible. Respect of ethical issues in this area and advancement of science are both important goals. These goals must be balanced, but one need not obstruct the other. Rather, countless researchers, clinicians, ethicists, policy makers, and others are working together to adhere to important ethical principles while advancing research that can help innumerable patients.

\section{ACKNOWLEDGMENTS}

The author would like to thank Melissa Conley and Lisa Chin for their assistance with this manuscript and the Greenwall and Kornfeld Foundations for their support.

\section{REFERENCES}

1. Department of Health, Education, and Welfare, The National Commission for the Protection of Human Subjects of Biomedical and Behavioral Research. The Belmont Report, Ethical Principles and Guidelines for the Protection of Human Subjects of Research. 1979Available at www.mri.edu.eg/mri/ The\%20Belmont\%20Report.pdf.

2. Omnibus Appropriations Act, 2009. Title V, §509. Available at: http://www.dol.gov/dol/budget/2008/PDF/CBJ-2008V3-07.pdf. Accessed September 2, 2009

3. Nova Science Now on PBS. The politics of stem cells. Available at: http://www.pbs.org/wgbh/nova/sciencenow/ dispatches/050413.html. Accessed September 2, 2009

4. National Research Council, Committee on Guidelines for Human Embryonic Stem Cell Research. Guidelines for human embryonic stem cell research. Available at: http:// www.nap.edu/catalog/11278.html. Accessed September 2, 2009

5. Klitzman R. The importance of social, cultural, and economic contexts, and empirical research in examining "undue inducement". Am J Bioeth 2005;5(5):19-21

6. National Academy of Sciences. The National Academies' Guidelines for Human Embryonic Stem Cell Research, 10. Washington, DC: The National Academies Press; 2005
7. National Academy of Sciences. Amendments to the National Academies' Guidelines for Human Embryonic Stem Cell Research. Washington, DC: The National Academies Press; 2007Available at: http://books.nap.edu/catalog.php?record_ id=11871\#toc. Accessed September 2, 2009

8. National Academy of Sciences. Amendments to the National Academies' Guidelines for Human Embryonic Stem Cell Research. Washington, DC: The National Academies Press; 2008Available at: http:/www.nap.edu/catalog.php?record_ id=12260. Accessed September 2, 2009

9. International Society for Stem Cell Research. Guidelines for the conduct of human embryonic stem cell research. Dec 21, 2006. Available at: http://www.isscr.org/guidelines/ISSCRhESCguidelines2006.pdf. Accessed September 2, 2009

10. Daley GQ, Ahrlund Richter L, Auerbach JM, et al. Ethics. The ISSCR guidelines for human embryonic stem cell research. Science 2007;315(5812):603-604

11. Okita K, Ichisaka T, Yamanaka S. Generation of germlinecompetent induced pluripotent stem cells. Nature 2007; 448(7151):313-317

12. Ramsay J. Donating eggs for research-should the HFEA reconsider its policy on payments to egg donors? Reprod Biomed Online 2007;15(1):25-33

13. Heng BC. International egg-sharing to provide donor oocytes for clinical assisted reproduction and derivation of nuclear transfer stem cells. Reprod Biomed Online 2005; 11(6):676-678

14. Hyun I. Fair payment or undue inducement? Nature 2006; 442(7103):629-630

15. Thompson C. Why we should, in fact, pay for egg donation. Regen Med 2007;2(2):203-209

16. Spar D. The egg trade-making sense of the market for human oocytes. N Engl J Med 2007;356(13):1289-1291

17. Steinbrook R. Egg donation and human embryonic stem-cell research. N Engl J Med 2006;354(4):324-326

18. Okie S. Stem-cell research-signposts and roadblocks. N Eng1 J Med 2005;353(1):1-5

19. Robertson JA. Compensation and egg donation for research. Fertil Steril 2006;86(6):1573-1575

20. Beeson D, Lippman A. Egg harvesting for stem cell research: medical risks and ethical problems. Reprod Biomed Online 2006;13(4):573-579

21. The Ethics Committee of the American Society for Reproductive Medicine. Financial incentives in recruitment of oocyte donors. Fertil Steril 2000;74(2):216-220

22. Mertes H, Pennings G. Oocyte donation for stem cell research. Hum Reprod 2007;22(3):629-634

23. Kanakas N, Mantzavinos T. Fertility drugs and gynecologic cancer. Ann N Y Acad Sci 2006;1092:265-278

24. Brinton LA, Moghissi KS, Scoccia B, Westhoff CL, Lamb EJ. Ovulation induction and cancer risk. Fertil Steril 2005; 83(2):261-274; quiz 525-526

25. United States Department of Health \& Human Services. Code of Federal Regulations, 2005. Title 45 Public Welfare, Part 46

26. Ripley E. A review of paying research participants: it's time to move beyond the ethical debate. J Empir Res Hum Res Ethics 2006;1(4):9-20

27. Emanuel EJ. Ending concerns about undue inducement. J Law Med Ethics 2004;32(1):100-105

28. Ethics Committee, American Society for Reproductive Medicine. Financial compensation of oocyte donors. Fertil Steril Ethics Committee Report 2007;88(2):305-309 
29. Vogel G. Ethical oocytes: available for a price. Science 2006; 313:155

30. Ethics Committee. American College of Obstetrics and Gynecology. Using preimplantation embryos for research. American College of Obstetricians and Gynecologists Committee Opinion No. 347. 2006Available at: http://www. acog.org/from_home/publications/ethics/co347.pdf. Accessed September 2, 2009

31. Klitzman R, Sauer MV. Payment of egg donors in stem cell research in the USA. Reprod Biomed Online 2009;18(5): 603-608

32. Empire State Stem Cell Board. Statement of the ESSCB on the compensation of oocyte donors. Available at: http:// www.stemcell.ny.gov/docs/ESSCB_Statement_on_Compen sation_of_Oocyte_Donors.pdf. Accessed September 2, 2009

33. Dickert N, Grady C. What's the price of a research subject? Approaches to payment for research participation N Engl J Med 1999;341(3):198-203

34. Klitzman R, Albala I, Siragusa J, Nelson K, Appelbaum P. The reporting of monetary compensation in research articles. J Empir Res Hum Res Ethics 2007;2(4):6167
35. Kliff S. Golden eggs: when donation funds an education. Newsweek 2007. Available at: www.msnbc.msn.com/id/ 12209274/site/newsweekpage/4/print/1/display.

36. Seibel MM, Kiessling A. Compensating egg donors: equal pay for equal time? N Engl J Med 1993;328(10):737

37. Klitzman R. Views of the process and content of reviews of HIV vaccine trials among members of US Institutional Review Boards and South African Research Ethics Committees. Dev World Bioeth 2007; Available at: http:// www.blackwell-synergy.com/doi/pdf/10.1111/j.14718847.2007.00189.x. Accessed September 2, 2009

38. Goldman J, Katz MI. Inconsistency and institutional review boards. JAMA 1982;248(2):197-202

39. Eaton WO. Reliability in ethical reviews: some initial empirical findings. Can Psychol 1983;24(1):14-18

40. Doob AN. The reliability of ethical reviews: is it desirable? Can Psychol 1983;24(4):269-270

41. Veatch RM. Problems with institutional review board inconsistency. JAMA 1982;248(2):179-180

42. Klitzman R, Albala I, Siragusa Jet al. Disclosure of information to potential subjects on research recruitment websites. IRB: Ethics \& Human Research 2008; Jan-Feb:15-20 